\title{
ANALISA SPASIAL LOKASI KORIDOR KOMERSIAL DISTRO DAN BUTIK DI KOTA PONTIANAK
}

\author{
Analyze of Commercial Space Corridor of Location Distro and \\ Boutique in Pontianak City
}

\author{
Nunik Hasriyanti ${ }^{1}$, Andi Zulestari ${ }^{2}$ and Julius Judhi ${ }^{3}$
}

Diterima: 17 Januari 2018

Disetujui: 9 Mei 2018

\begin{abstract}
Abstrak: Kota Pontianak merupakan kota jasa yang saat ini berkembang pesat dan pertumbuhan sektor perdagangan sebagai pusat aktifitas ekonomi yang menjadi daya tarik masyarakat untuk melakukan usaha perdagangan berupa distro dan butik. Menjamurnya pusat pertokoan menyebabkan segi positif bagi pendapatan daerah Kota Pontianak dan disisi lain mengakibatkan segi negatif yaitu kemacetan, kurangnya lapangan parkir, papan iklan yang mengganggu visual kota serta merubah image kawasan. Kajian ini mengevaluasi lokasi pusat pertokoan distro dan butik menggunakan Analytic Hierarchy Process (AHP), untuk mendapatkan alternative lokasi terbaik dalam pemilihan lokasi komersial distro dan butik di Kota Pontianak. Hasilnya bahwa perhitungan data terhadap berbagai aspek yang menjadi kriteria yaitu aspek Fisik, Sosial, ekonomi dan aksesibilitas dimana hirarki tertinggi adalah aspek ekonomi dengan sub aspek yang tertinggi adalah daya tarik investasi dimana yang menjadi tolak ukur kriteria adalah perputaran uang jumlah yang besar, ramai pengunjung (weekend), harga lahan yang terus meningkat, bebas dari pungutan liar yang dapat menjadi beban bagi para pengusaha / investor. Sedangkan dari 10 subaspek kriteria untuk menilai tiga koridor jalan dalam penentuan lokasi distro dan butik, didapt hasil bahwa koridor Jalan Gusti hamzah unggul dengan 9 sub-aspek $(0,5253)$ dibandingkan dengan 2 koridor lainnya yaitu Jalan M. Yamin $(0,2555)$ dan Jalan Danau Sentarum $(0,2154)$.
\end{abstract}

\section{Keyword in Bahasa: koridor, komersial, distro dan butik, AHP}

\begin{abstract}
Pontianak city is a city that is currently growing rapidly and growing rapidly as a center of economic activity that attracts people to do business in the form of distro and boutique trade. The proliferation of shopping centers arose positive aspects for the city of Pontianak and on the other side developed negative aspects of traffic jams, lack of parking space, billboards intended for visualization and changes in the image of the region. This study takes the location of the center of department stores and boutiques using Analytic Hierarchy Process (AHP), to get the best alternative in Pontianak City. Calculation of results data on various aspects that will be used are Physical, Social, Economic and accessibility aspects which are economic aspect with subference which is the investment attraction becoming the benchmark is turnover of big number, crowded visitor (weekend), increased, free from illegal levies that could be a burden for entrepreneurs / investors. While from 10 sub-aspect of criteria to give three way in determining the location of distribution and boutique, conducted at Jalan Gusti hamzah superior with 9 sub-aspect $(0,5253)$ compared to 2 other corridors that is Jalan M. Yamin $(0$, 2555) and Danau Sentarum Road (0.2154).
\end{abstract}

Keywords: instructions, journal, tataloka, writing

\footnotetext{
${ }^{1}$ Politeknik Negeri Pontianak
} 


\section{PENDAHULUAN}

Perbedaan kota (urban) dan desa (rural) adalah percepatan pertumbuhan dan perubahannya. Kota yang berkembang sangat identik dengan pertumbuhan dan perubahan yang cepat seperti; percepatan daerah terbangun, perubahan fungsi lahan, perumbuhan penduduk dan perkembangan ekonomi. Salah satu contoh adalah kawasan bisnis dan perdagangan diperkotaan yang menjadi magnet (Mokodongan, 2016), banyak tata guna lahan yang berubah fungsi, yang dulunya daerah perumahan berubah fungsi menjadi kawasan bisnis, dan perdagangan seperti mall, pertokoan, ruko, distro, butik, hotel dan restoran, dan jasa. Potensi yang dimiliki pusat kota tersebut menyebabkan berkembangnya pusat kegiatan perdagangan dan bisnis karena secara ekonomi pusat kota sangat menguntungkan dan mampu memberikan sumbangan terbesar bagi struktur perekonomian kota. Spreiregen (1965:124) mengatakan bahwa pusat kota tidak pernah statis dalam bentuk dan fungsinya.

Bangunan-bangunan adalah elemen-elemen urban design dan signage atau papan reklame yang menempel pada bangunan-bangunan mempunyai pengaruh yang besar pada kualitas visual area urban (Carr, 1973 dalam Mandaka, 2015). Nugrahini (2015) menggambarkan koridor merupakan jalan (path) yang dibentuk oleh dua deretean massa (bangunan atau pohon) membentuk sebuah ruang. Koridor jalan merupakan ruangluar yang berfungsi sebagai sarana transportasi atau pergerakan orang. Menurut Askari et al,2013 dalam Suri dan Sufiri, 2015 bahwa identitas sebuah distrik kawasan koridor kota direpresentasikan oleh bentuk fasad bangunan yang memiliki keunikan tersendiri. Sehingga dalam menentukan fungsi khusus sebuah koridor juga harus mempertimbangkan bentuk visual bangunan yang ada di sekitarnya. Menurut Krier (1979) sebuah commercial street harus dirancangberbeda dengan jalan yang murni dengan hunian (Tobing dkk, 2014). Jalan ini harus lebih sempit, memungkinkan orang untuk melihat barang-barang yang ditampilkan di windows display toko-toko seberang jalan tanpa harus menyeberang. Namun untuk jalan-jalan yang mengakomodasi kendaraan dengan kecepatan relatif tinggi seperti halnya yang terjadi di wilayah sub urban, tipologi bentuk elemen ruang kota harus mempertimbangkan moda transportasi yang digunakan. Cullen (1961) menyatakan pada prinsipnya content pada sebuah koridor terdiri dari unsur-unsur gaya dab netuk arsitektur, skala, material, dan lay out, warna, tekstur, ragam hias, dan karakter.

Geliat bisnis fashion kian tumbuh dan berkembang. Apalagi saat ini fashion sudah menjadi kebutuhan primer manusia. Ini yang membuat fashion menjadi bisnis yang menarik dijalankan. Salah satu bisnis fashion yang menjanjikan adalah membuka usaha distro, butik dan factory outlet. Untuk ukuran Kota Pontianak bisnis ini terus tumbuh dan berkembang dan tidak sulit menemukan distro, butik dan factory outlet di Kota khatulistiwa ini. Dengan adanya penetapan Sistem Pusat Pelayanan Kota pada daerah perkotaan, diharapkan agar terjadi perkembangan yang merata pada daerah perkotaan dan membuat sub-sub perkembangan baru. Perkembangan kawasan kota yang merata agar tidak membebankan pusat kota, sehingga terbagi dalam Pusat Pelayanan Kota (PPK), Sub Pusat Pelayanan Kota (SPPK), dan Pusat Lingkungan (PL). PPK meliputi Kelurahan Mariana, Tengah, Darat Sekip, sebagian Kelurahan Benua Melayu Darat di Kecamatan Pontianak Kota, sebagian Kelurahan Benua Melayu Laut, Kelurahan Akcaya, sebagian Kelurahan Parit Tokaya di Kecamatan Pontianak Selatan, serta sebagian Kelurahan Siantan Tengah Di Kecamatan Pontianak Utara dan Kelurahan Dalam Bugis di Kecamatan Pontianak Timur yang memiliki fungsi-fungsi yang meliputi : perdagangan dan jasa; perkantoran; pariwisata skala regional; simpul transportasi regional; dan perumahan kepadatan tinggi. 


\section{METODE}

Analytical Hierarchy Process (AHP) adalah suatu metode unggul untuk memilih aktivitas yang bersaing atau banyak alternatif berdasarkan kriteria tertentu (Taufan, 1996). Atau khusus. Kriteria dapat bersifat kuantitatif atau kualitatif, dan bahkan kriteria kuantitatif ditangani dengan struktur kesukaan pengambil keputusan daripada berdasarkan angka.

Struktur sebuah model AHP adalah model dari sebuah pohon terbaik. Ada suatu tujuan tunggal di puncak pohon yang mewakili tujuan dari masalah pengambilan keputusan. Seratus persen bobot keputusan adan di titik ini. Tepat dibawah tujuan adalah titik daun yang menunjukkkan kriteria, baik kualitatif maupun kuantitatif. Bobot Tujuan harus dibagi diantara titik-titik kriteria berdasarkan rating. Pendekatan AHP menggunakan skala banding berpasangan menurut Saaty (1993). Skala banding berpasangan tersebut disajikan pada tabel berikut ini.

\section{Tahapan dalam AHP}

Bobot dari tiap-tiap kriteria adalah $100 \%$ dibagi dengan bobot titik-titik kriteria berdasarkan rating. Setiap alternatif dibandingkan dengan masing-masing kriteria.

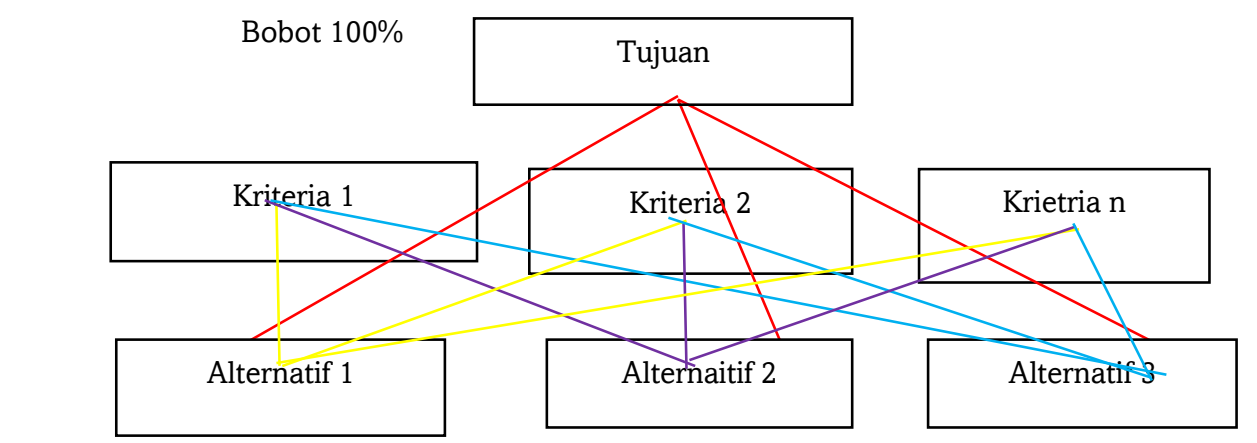

Sumber : Saaty, 1993

Gambar 1. Diagram Struktur Hirarki AHP Menurut Saaty

Tabel 1. Skala Banding Berpasangan Menurut Saaty (1993)

\begin{tabular}{|c|c|c|}
\hline $\begin{array}{l}\text { Intensitas } \\
\text { Pentingnya }\end{array}$ & Definisi & Penjelasan \\
\hline 1 & Kedua elemen sama pentingnya & $\begin{array}{l}\text { Sumbang peran dua elemen sama besar pada sifat } \\
\text { tersebut (dua elemen mempunyai pengaruh yang } \\
\text { sama besar terhadap tujuan) }\end{array}$ \\
\hline 3 & $\begin{array}{l}\text { Elemen satu sedikit lebih penting daripada } \\
\text { yang lainnya }\end{array}$ & $\begin{array}{l}\text { Pengalaman dan pertimbangan sedikit } \\
\text { menyokong satu elemen atas elemen yang lain }\end{array}$ \\
\hline 5 & $\begin{array}{l}\text { Elemen satu lebih penting disbanding yang } \\
\text { lain }\end{array}$ & $\begin{array}{l}\text { Pengalaman dan pertimbangan dengan kuat } \\
\text { mendukung satu elemen atas yang lain }\end{array}$ \\
\hline 7 & $\begin{array}{l}\text { Elemen satu jelas lebih penting dari elemen } \\
\text { yang lain }\end{array}$ & $\begin{array}{l}\text { Satu elemen dengan kuat dominansinya telah } \\
\text { terlihat dalam praktek }\end{array}$ \\
\hline 9 & $\begin{array}{l}\text { Elemen satu mutlak lebih penting dari elemen } \\
\text { yang lain }\end{array}$ & $\begin{array}{l}\text { Bukti yang mendukung elemen yang satu } \\
\text { terhadap elemen lain memiliki tingkat [enegasan } \\
\text { tertinggi yang mungkinmenguatkan }\end{array}$ \\
\hline $2,4,6,8$ & $\begin{array}{l}\text { Nilai-nilai diantara dua pertimbangan yang } \\
\text { berdekatan }\end{array}$ & $\begin{array}{l}\text { Nilai ini diberikan bila ada dua kompromi di } \\
\text { antara dua pilihan }\end{array}$ \\
\hline Kebalikan & $\begin{array}{l}\text { Jika untuk aktivitas i mendapat satu angka bila } \\
\text { dibandingkan dengan aktivitas j, maka j } \\
\text { mempunyai nilai kebalikannya bila } \\
\text { dibandingkan dengan i }\end{array}$ & \\
\hline
\end{tabular}

Sumber: Saaty, 1993 


\section{HASIL DAN PEMBAHASAN}

Penentuan dari koridor distro dan butik outlet yang tepat haruslah memperhatikan beberapa faktor seperti : kesesuaian dengan peruntukan tata guna lahan, mampu meningkatkan ekonomi wilayah disekitarnya, memperhatikan faktor lingkungan / nilai historis suatu kawasan, dan lain lain. Kini banyak kita temukan distro dan butik outlet yang tidak sesuai dengan peruntukan lahannya karena itulah pada makalah ini kami mencoba untuk memperbandingkan beberapa koridor perdagangan dan jasa yang ada di Kota Pontianak, sehingga dapat ditentukan lokasi yang tepat bagi pembangunan \& pengembangan distro dan butik outlet dimasa yang akan datang. Pengaruh kegiatan komersial terhadap perkembangan koridor jalan akan mencerminkan suatu bentuk aktifitas perdagangan suatu kota yang meliputi aktivitas perdagangan retail dan pengusahaan jasa skala lokal sehingga akan memiliki pengaruh besar terhadap kegiatan ekonomi kota (Murti, 2013). Selain itu visualisasi pengamat ketika akan memasuki kawasan koridor jalan akan memberikan pengaruh kuat antar karakter bangunan yang ada, sehingga penting untuk menjadi pertimbangan dalam menentukan letak lokasi bangunan komersial (Widiantara, 2017).

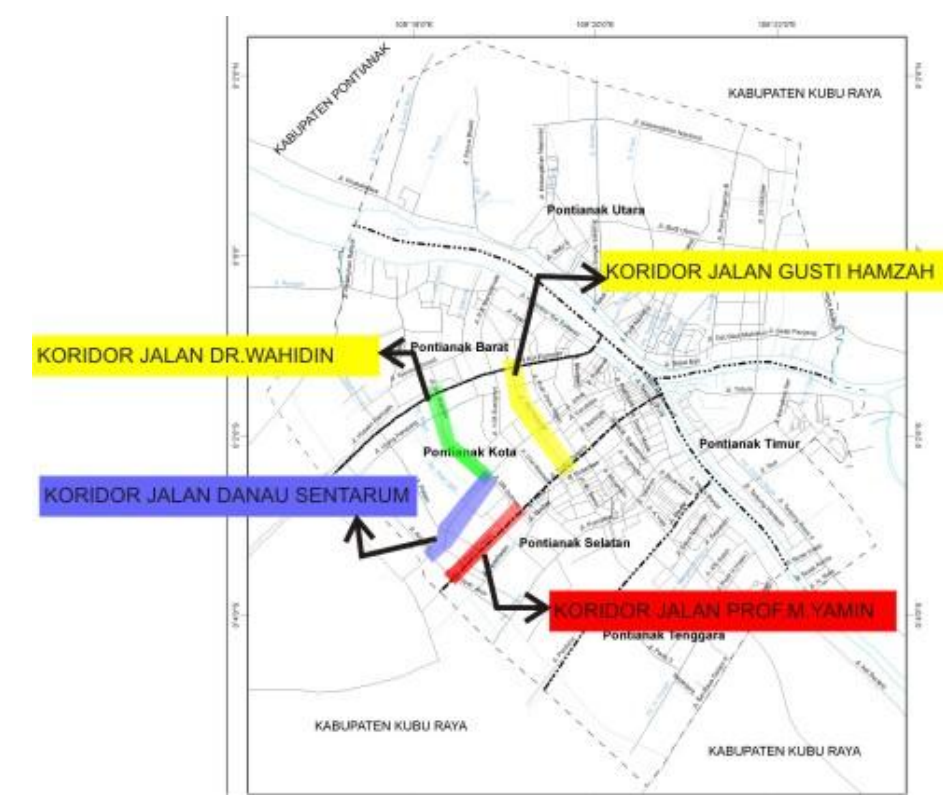

Sumber: Bappeda Kota Pontianak, 2017, Analisis peta, 2017

Gambar 1. Peta Lokasi Amatan pada Koridor Komersial di Kota Pontianak

Berikut adalah penjelasan mengenai kondisi eksisting dari 3 buah koridor jalan yang merupakan alternatif lokasi dari distro dan butik outlet di Kota Pontianak, yaitu :

\section{Koridor Jalan Danau Sentarum}

Jalan Danau Sentarum termasuk kedalam Jalan Kolektor Primer dengan peruntukan sebagai daerah komersial dan permukiman yang mengedepankan fungsi perdagangan dan hunian. Wilayah studi yang diamati dimulai dari perempatan Jalan Ali Anyang - Jalan Dr. Sutomo sampai pertigaan Jalan Danau Sentarum - Jalan Ampera. 


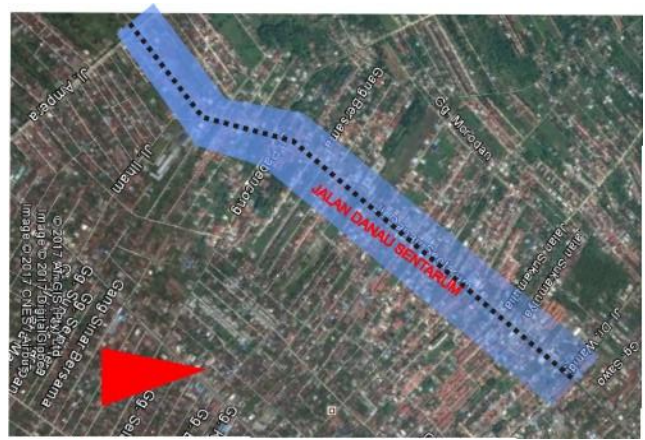

Sumber: GoogleEarth, 2017, Hasil Analisis peta, 2017

\section{Gambar 2. Peta Koridor Jalan Danau Sentarum mulai dari perempatan Jalan DR. Sutomo hinga pertigaan Jalan Ampera}

Adapun berdasarkan pengamatan kami ruas Jalan Danau Sentarum banyak ditemukan fungsi dengan tata guna lahan yang berlainan seperti perumahan, perkantoran, perdagangan, pendidikan, pertokoan dan perkebunan. Selain itu juga di ruas jalan ini terdapat banyak penghijauan / pepohonan yang menjadikan koridor ini agak lebih sejuk dan nyaman untuk dilalui serta arus lalu lintas yang dapat dilewati oleh kendaraan dengan arah yang saling berlawanan (dua arah).

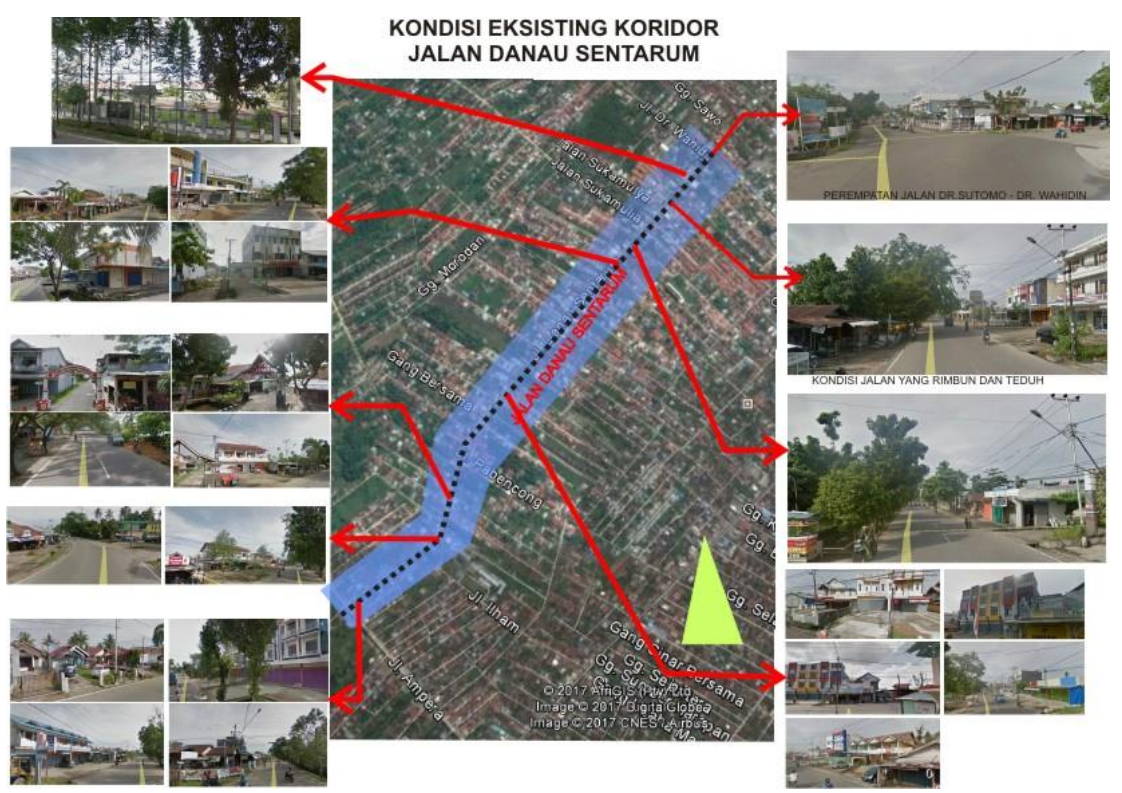

Sumber: GoogleEarth, 2017, Hasil Analisis peta, 2017. Pengamatan Lapangan, 2017

Gambar 3. Kondisi eksisting ruas koridor Jalan Danau Sentarum

Sedangkan pada ruas Jalan Danau Sentarum ini arus lalu-lintas bisa dilalui dua arah, serta ruas jalan yang didominasi oleh bangunan pertokoan semacam ruko dan bercampur dengan para pedagang kaki lima (PKL) yang berjualan di pinggiran jalan dan bahkan di trotoar yang membuat koridor jalan ini terkesan kumuh dan tidak tertata selain itu juga ketidakadaan vegetasi / pepohonan di sepanjang koridor ini turut menambah ketidak nyaman pada ruas jalan ini pada beberapa titik ruas jalan yang didominasi oleh bangunan pertokoan. 


\section{Koridor Jalan Prof M.Yamin}

Jalan M. Yamin digolongkan kedalam jalan kolektor primer yang menghubungkan Jalan Sutan Syahrir dengan Jalan Ampera dengan peruntukan tata guna lahan sebagai kawasan perdagangan. Ruas Jalan M. Yamin yang diamati dimulai dari perempatan Jalan Sutan Syahrir - DR. Sutomo hingga perempatan Ampera. Berdasarkan hasil pengamatan di lapangan kondisi jalan berada sangat baik dengan sistem drainase tertutup, selain itu juga pada bahu jalan disediakan trotoar bagi para pejalan kaki namun tidak adanya pepohonan membuat koridor jalan ini tidak nyaman bagi pejalan kaki.

Sepanjang pengamatan kami terdapat beragam jenis kegiatan disepanjang koridor ini, mulai dari pertokoan, perkantoran , rumah makan, pendidikan, pemerintahan, sarana ibadah, pompa bensin dll. Walaupun terdapat PKL di beberapa titik namun tidak menciptakan kesemrawutan karena umumnya mereka berjualan di emperan toko. Kemacetan pada ruas jalan ini hanya berada pada simpul Pasar Tradisional Kemuning. Selain itu arus lalu-lintas di jalan ini berlaku dua arah sehingga memudahkan aksesibilitas para pengguna jalan baik yang dari utara menuju selatan maupun yang berasal dari selatan menuju daerah utara. Namun sangat disayangkan tidak adanya pemisah badan jalan yang bersifat permanen, saat ini pemisah hanya berupa cat putih sehingga sangat berbahaya bagi mereka yang ingin menyebrang. Jalan M. Yamin secara letak / posisi sangatlah menguntungkan karena dekat dengan pusat kota.

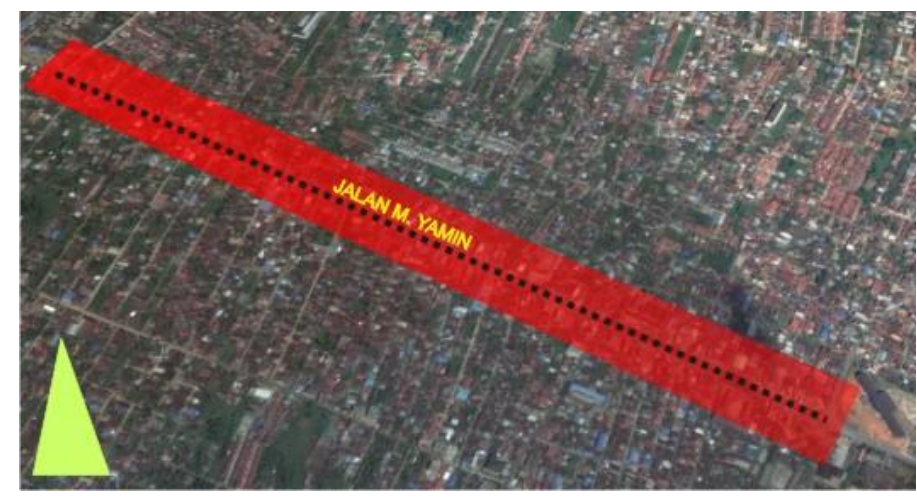

Sumber: GoogleEarth, 2017, Hasil Analisis peta, 201. Pengamatan Lapangan, 2017

Gambar 4. Koridor M. Yamin mulai dari perempatan Jalan St. Syahrir - DR. Sutomo hingg ake perempatan Jalan Ampera-Jalan Perdamaian

Koridor M. Yamin pada perempatan Jalan Sutomo dan Jalan St. Syahrir didominasi oleh fungsi perdagangan berupa toko-toko makanan dan warung kopi. Juga terdapat gerobak-gerobak PKL pada sore hari yang menjual gorengan dan kue-kue. Di sekitar in juga terdapat pasar Kemuning yang merupakan pasar tradisional yang diperuntukan bagi masyarakat di daerah Kota Baru. Selain itu terdapat fungsi pendidikan yaitu sekolah terpadu SD dan SMP yang posisinya tepat berada di depan Pasar Kemuning sehingga pada pagi hari saat anak-anak pergi sekolah dan aktifitas pasar dimulai akan terjadi kemacetan di jalan sekitar sekolah dan pasar. Kemacetan juga terjadi pada siang hari pada saat anakanaka pulang sekolah. 


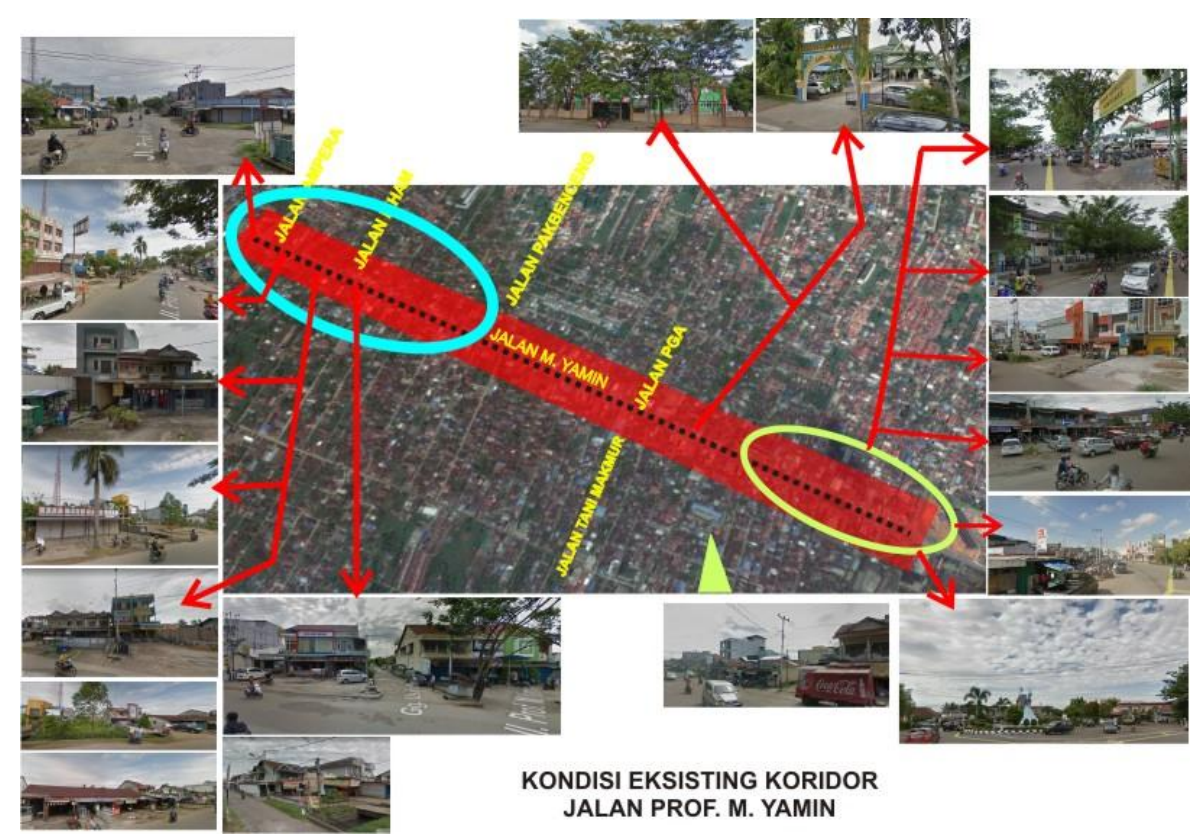

Sumber: GoogleEarth, 2017, Hasil Analisis peta, 2017. Pengamatan Lapangan, 2017 Gambar 5. Koridor Jalan Prof. M. Yamin pada perempatan di Jalan Sutomo - St. Syahrir dan perempatan Jalan Ampera - Jalan M. Yamin

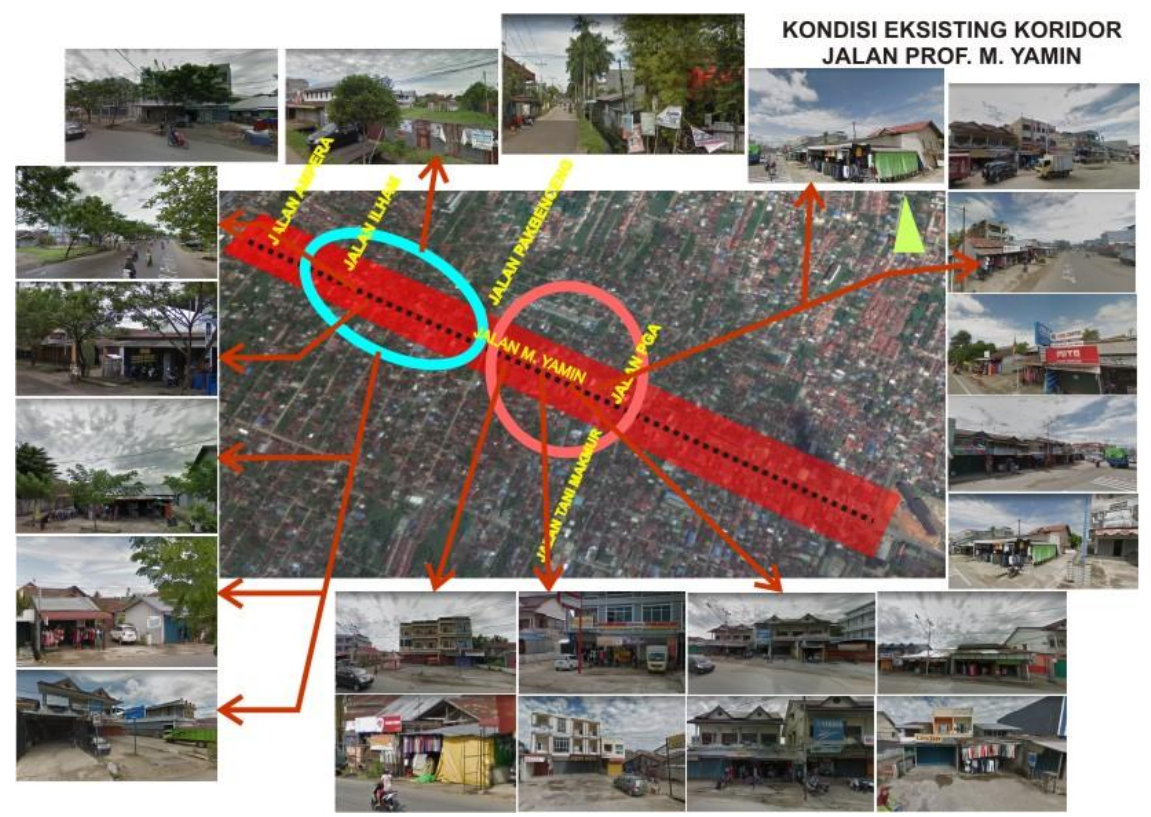

Sumber: GoogleEarth, 2017, Hasil Analisis peta, 201. Pengamatan Lapangan, 2017

Gambar 6. Kondisi eksisting koridor Jalan Prof. M. Yamin yang dipenuhi oleh fungsi perdagangan

\section{Koridor Jalan Gusti Hamzah}

Menurut pengamatan yang kami lakukan di Jalan Gusti Hamzah, arus lalu-lintas di jalan ini berlaku dua arah dimana tiap jalur terdiri atas dua lajur. Selain itu fungsi bangunan disepanjang jalan ini didominasi oleh bangunan hunian, rumah makan, resto cafe, dan toko-toko berupa ruko yang tersebar hampir merata di sepanjang jalan Gusti Hamzah ini. 
Jalan Gusti Hamzah merupakan jalan penghubung antara Jalan Putri Candramidi di Pontianak Kota dengan daerah Sungai Jawi di Kecamatan Pontianak Barat, sehingga keberadaan jalan ini cukup membantu mengurangi kemacetan di dalam pusat kota. Untuk pengembangan kedepannya kawasaan ini sangatlah potensial selain karena infrastrukturnya yang memadai juga karena lahan yang tersedia masih banyak dan berlimpah, juga dengan direncanakannya jalur biskota di koridor ini maka akan mempermudah aksesibilitas masyarakat yang ingin ke daerah ini. Namun untuk saat ini kawasan ini masih terlihat lengang dan aktivitas warga sekitar yang terbatas pada jam jam tertentu saja.

\section{Penentuan Lokasi Koridor Distro dan Butik Outlet}

Keberadaan distro dan butik outlet patut didukung keberadaannya karena mampu mendorong ekonomi lokal dan membuka lapangan pekerjaan, tetapi dampak - dampak negatif dari distro dan butik outlet perlu menjadi konsiderasi bagi keberadaannya di sebuah daerah, karena itulah dirasakan perlunya keberadaan koridor komersial yang dikhususkan bagi keberadaan distro dan butik outlet guna mengeliminasir dampak negatif. Dalam bab bab sebelumnya telah dijelaskan mengenai teori dari karakteristik kawasan komersial baik itu dari sisi aktivitasnya maupun dari fungsi jalan. Selain itu pada bab tiga berisi tentang penjelasan beberapa alternatif lokasi koridor distro dan butik outlet, yaitu Jalan Danau Sentarum, Jalan M. Yamin,Jalan DR. Wahidin dan Jalan Gusti Hamzah. Koridor jalan tersebut dipilih berdasarkan fungsi tata guna lahan sebagai kawasan komersial; perdagangan dan jasa (RTRW Kota Pontianak), selain itu aksesnya yang berdekatan dengan pusat kota dan aksesnya yang berdekatan dengan jalan utama kota, mengingat kebanyakan pengunjung distro dan butik outlet berasal dari luar kota. Guna mendapatkan alternatif lokasi yang ideal kami mempergunakan analisis AHP (Analytic Hierarchy Process) dengan memperbandingkan faktor - faktor yang terdiri atas aspek dan sub aspek.

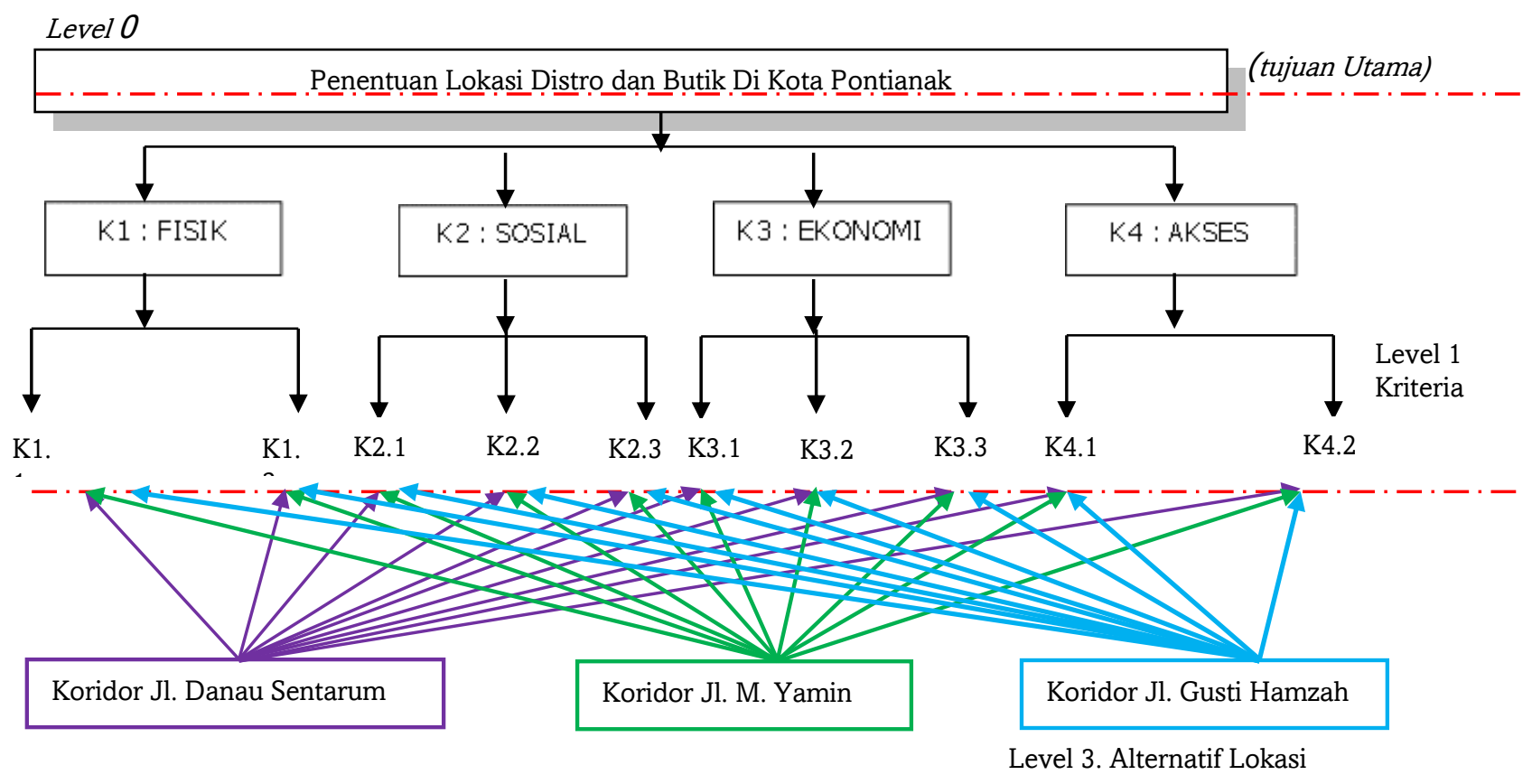

Sumber: Hasil Analisis peta, 201. Pengamatan Lapangan, 2017

Gambar 7. Struktur Hirarki Faktor-Faktor Utama Untuk Penentuan LOkasi Koridor Distro dan Butik di Kota Pontianak 
Keterangan gambar :
K1 Fisik
K1.1. Fisik Eksternal
: K1.2. Fisik Internal
K2 Sosial $\quad$ : K2.1. Nilai Historis Kawasan
K2.2. Nilai Budaya
: K2.3. Aspek Legalitas
K3 Ekonomi $\quad$ : K3.1. Kontribusi terhadap PAD
: K3.2. Daya Tarik Investasi
: K3.3. Peningkatan Ekonomi Masyrakat Miskin
K4 Akses : K4.1. Aspek Transportasi
K4.2. Aspek Strategis

\section{Penentuan dan Pembobotan Kriteria}

Kriteria-kriteria yang ditentukan sebagai faktor yang mempengaruhi didalam penentuan lokasi koridor distro dan butik didefinisikan berdasarkan relevansinnya dengan tujuan mengetahui tingkat kepentingan faktor-faktor sehingga dapat diketahui faktor terpenting yang mempengaruhi penentuan lokasi tersebut.(Hudalah, 2004)

Tabel 2. Kriteria dan Tolok Ukur Dalam Penentuan Lokasi Koridor Distro dan Butik di Kota Pontianak

\begin{tabular}{|c|c|c|}
\hline & Kriteria & Keterangan (sebagai tolok ukur) \\
\hline Aspek & Sub Aspek & \\
\hline \multirow[t]{2}{*}{ Fisik } & $\begin{array}{l}\text { Fisik eksternal } \\
\text { (sekitar lahan) }\end{array}$ & $\begin{array}{ll}\text { - } & \text { Dekat dengan fasilitas pendukung, seperti pusat kota, } \\
\text { penginapan, rumahmakan, café restoran } \\
\text { - } \\
\text { Bebas dari ancaman bencana alam seperti banjir, longsor } \\
\text { Image/ciri dari kawasan mendukung untuk menjadi } \\
\text { daerah perdagangan komersil }\end{array}$ \\
\hline & Fisik Internal & $\begin{array}{ll}\text { - } & \text { Kondisi kawasan yang lebih nyaman } \\
\text { - } & \text { Ketersediaan lahan untuk pengambangan di masayang } \\
\text { akan datang }\end{array}$ \\
\hline \multirow{3}{*}{ Ekonomi } & $\begin{array}{l}\text { Kontribusi } \\
\text { terhadap PAD }\end{array}$ & $\begin{array}{ll} & \text { Meningkatnya PAD dari pajak, retribusi dan pungutan } \\
& \text { lainnya } \\
\text { - } & \text { Sebagai salah satu sumber pendapatan bagi PAD }\end{array}$ \\
\hline & $\begin{array}{l}\text { Darik Tarik } \\
\text { investasi }\end{array}$ & $\begin{array}{ll}- & \text { Perputaran uang 9(cash flow) dalam jumlah besar } \\
\text { - } & \text { Ramai oleh pengunjung terutama pada saat weekend } \\
\text { - } & \text { Harga lahan yang terus meningkat } \\
\text { - } & \text { Bebas dari pungutan liar yang dapat menjadi bebanbagi } \\
& \text { para pengusaha investor }\end{array}$ \\
\hline & $\begin{array}{l}\text { Peningkatan } \\
\text { ekonomi } \\
\text { masyarakat miskin }\end{array}$ & $\begin{array}{l}\text { - Meningkatkan usaha/perdagangan masyarakat golongan } \\
\text { menengah ke bawah } \\
\text { - } \quad \text { Menyerap tenaga kerja }\end{array}$ \\
\hline \multirow{3}{*}{ Sosial } & $\begin{array}{l}\text { Nilai historis } \\
\text { kawasan }\end{array}$ & $\begin{array}{ll}- & \text { Peranan dari kawasandi masa lampau } \\
\text { - } & \text { Bangunan bersejarah di akwasan tersebut } \\
\text { - } & \text { Sejarahperkembangan sebuah kawasan }\end{array}$ \\
\hline & Nilai budaya & $\begin{array}{l}\text { Tradisi/kebiasaan masyarakat setempat sebagai nilai } \\
\text { tambah bagi akwasan tersebut } \\
\text { - Local genius darimasyarakat setempat untuk } \\
\text { menciptakan sebuah kawasan perdagangan dengan local } \\
\text { taste } \\
\text { - Partisipasi masyarakat setempat }\end{array}$ \\
\hline & Aspek legal & $\begin{array}{l}\text { Kesesuaian dengan peraturan tata ruang dan peraturan } \\
\text { bangunan yang ditetapkan oleh pemerintah daerah Kota } \\
\text { Pontianak }\end{array}$ \\
\hline Akses & Aspek transportasi & $\begin{array}{ll}\text { - } & \text { Dekat dengan terminal oplet dan moda transportasi } \\
& \text { lainnya } \\
\text { - } & \text { Dilewati oleh rute angkutan umum } \\
\text { - } & \text { Kondisi jalan yang baik }\end{array}$ \\
\hline
\end{tabular}




\begin{tabular}{|c|c|c|}
\hline \multicolumn{2}{|c|}{ Kriteria } & \multirow[t]{2}{*}{ Keterangan (sebagai tolok ukur) } \\
\hline Aspek & Sub Aspek & \\
\hline & & $\begin{array}{ll}- & \text { Lebar jalan yang memadai } \\
- & \text { Lalu lintas lancer/tidak macet } \\
\end{array}$ \\
\hline & egis & $\begin{array}{ll}\text { - } & \text { dekat/mudah dicapai dari pusat kota } \\
\text { - } & \text { perjalanan untuk mencapai ke kawasan tersebut tidak } \\
\text { menghabiskan waktu yang lama }\end{array}$ \\
\hline
\end{tabular}

Sumber : Hasil Analisis, 2017

\section{Pembobotan Kriteria}

Setelah menghitung tingkat kepentingan dari suatu kriteria yang dapat mempengaruhi penentuan lokasi koridor distro dan butik outlet, dapat diketahui tingkat kepentingan mana yang paling mempengaruhi (nilai bobot hitungannya lebih besar daripada yang lainnya). Adapun hasil pembobotan yang telah dilakukan pada kriteria aspek fisik, sosial, ekonomi dan faktor aksesbilitas, dapat dilihat pada tabel kriteria dan tolok ukur. Dalam penelitian ini penulis melakukan simulasi dengan menyebarkan kuesioner kepada 50 orang responden.

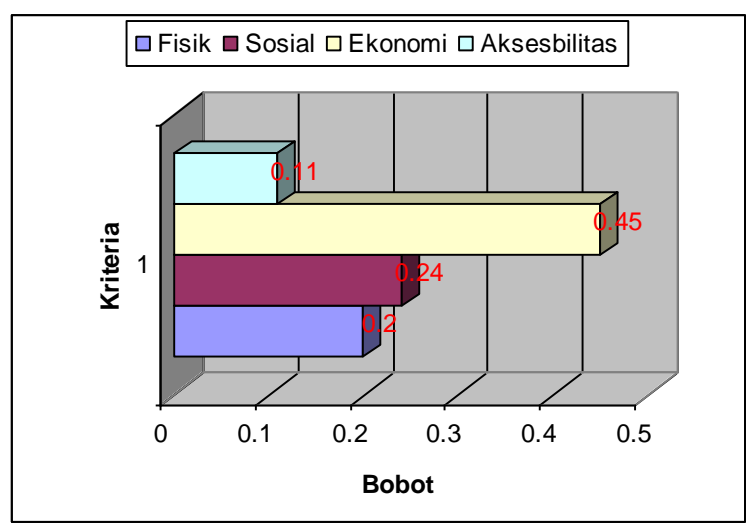

Sumber: Hasil Analisis , 2017.

\section{Gambar 7. Diagram Bobot Kriteria yang Mempengaruhi Penentuan Lokasi Korisor Distro dan Butik di Kota Pontianak}

Dapat disimpulkan dari diagram diatas bobot kriteria-kriteria yang dapat mempengaruhi penentuan lokasi koridor distro dan butik di kota Pontianak maka kriteria ekonomi yang paling mempengaruhi didalam penentuan lokasi distro dan butik outlet dengan bobot sebesar 0.45 , kemudian disusul oleh kriteria sosial dengan bobot sebesar 0.24 kemudian kriteria fisik dengan bobot sebesar 0,2 dan terakhir aksesibilitas dengan skor 0.11 .

\section{Pembobotan Sub Aspek}

Setelah melakukan penilaian 4 aspek diatas, berikutnya adalah penilian bobot subaspek fisik, sub-aspek sosial, sub-aspek ekonomi dan sub-aspek aksesibilitas. Total subaspek adalah ada 10 (sepuluh), diantaranya dua sub aspek fisik, tiga sub aspek sosial, tiga sub aspek ekonomi dan dua sub aspek aksesibilitas. Adapun untuk lebih jelas besaran bobot penilaian masing-masing sub-aspek dapat dijelasan berikut ini. 
a. Penilaian bobot sub aspek dari aspek fisik

Adapun bobot penilaian sub-aspek fisik yang tertinggi adalah fisik internal (0.83), angka ini sangat tinggi jika dibandingkan dengan fisik eksternal. Untuk lebih jelas dapat dilihat pada diagram berikut ini

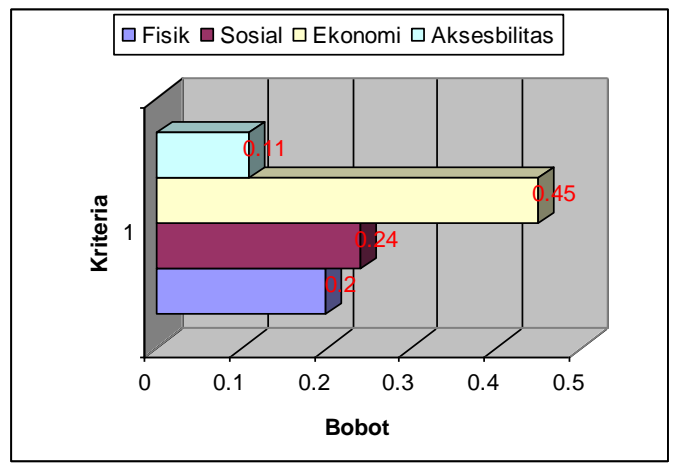

Sumber: Hasil Analisis, 2017.

\section{Gambar 8. Diagram Batang Bobot Sub- Aspek Dari Aspek Fisik yang Mempengaruhi Penentuan Lokasi Koridor Distro Dan Butik di Kota Pontianak}

b. Penilaian bobot sub aspek dari aspek sosial

Pada penilaian bobot sub-aspek sosial, aspek legal sangat mendominasi dari sub aspek lainnya yaitu nilai historis dan nilai budaya. Untuk lebih jelas dapat dilihat pada diagram berikut ini.

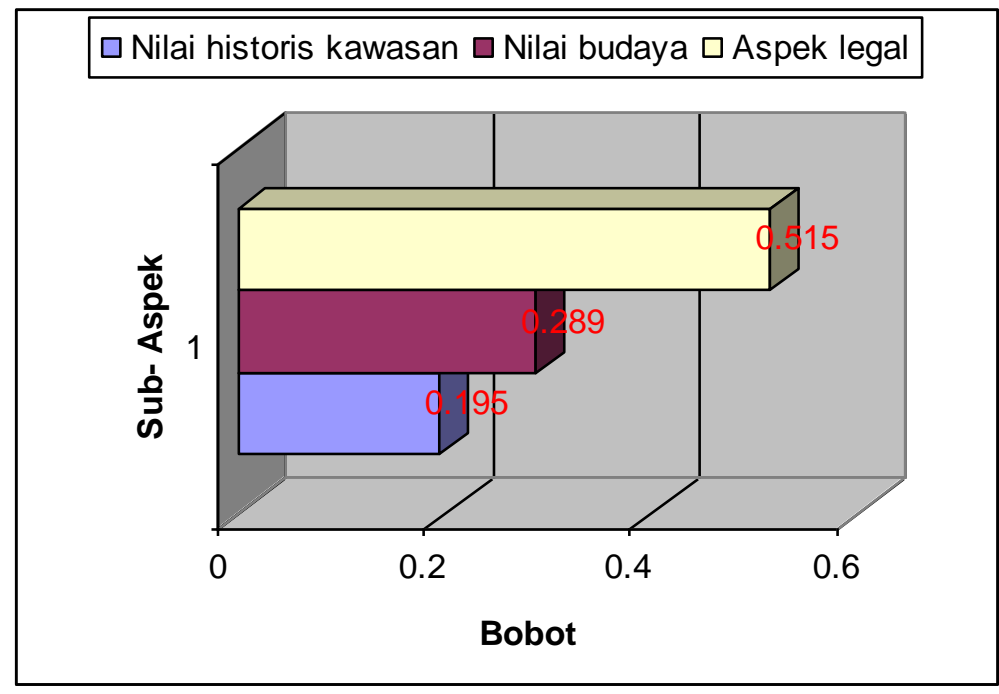

Sumber: Hasil Analisis peta, 201. Pengamatan Lapangan, 2017

Gambar 9. Diagram Batang Bobot Sub- Aspek dari Aspek Sosial yang Mempengaruhi Penentuan Lokasi Koridor Distro dan Butik di Kota Pontianak

c. Penilaian bobot sub aspek dari aspek ekonomi

Dari ke tiga sub aspek ekonomi, bobot penilaian tertinggi adalah daya tarik investasi, selanjutnya peningkatan ekonomi masyarakat miskin dan yang terakhir adalah kontribusi terhadap Pendapatan Asli Daerah (PAD), dalam hal ini pendapatan Kota Pontianak. Untuk lebih jelas dapat dilihat pada diagram berikut ini. 


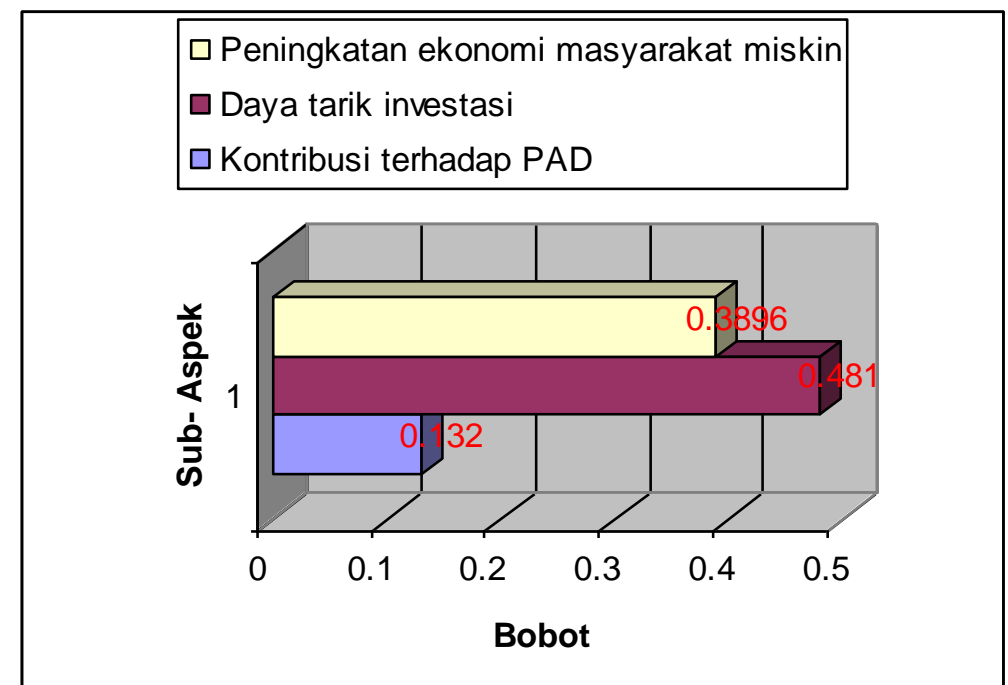

Sumber: Hasil Analisis , 2017

Gambar 10. Diagram Batang Bobot Sub- Aspek dari Aspek Ekonomi yang Mempengaruhi Penentuan Lokasi Koridor Distro dan Butik di Kota Pontianak

d. Penilaian bobot sub aspek dari aspek aksesibilitas

Sub aspek selanjutnya adalah sub aspek aksesibilitas, dari hasil perhitungan bobot penilaian didapati hasil sub aspek strategis yang diunggulkan dengan (bobot penilaian 0,776), hal ini menunjukan tolok ukur dekat dengan jalan tol dan dekat / mudah dicapai dari pusat kota perjalanan untuk mencapai ke kawasan tersebut tidak menghabiskan waktu yang lama. Untuk lebih jelas dapat dilihat pada diagram berikut ini.

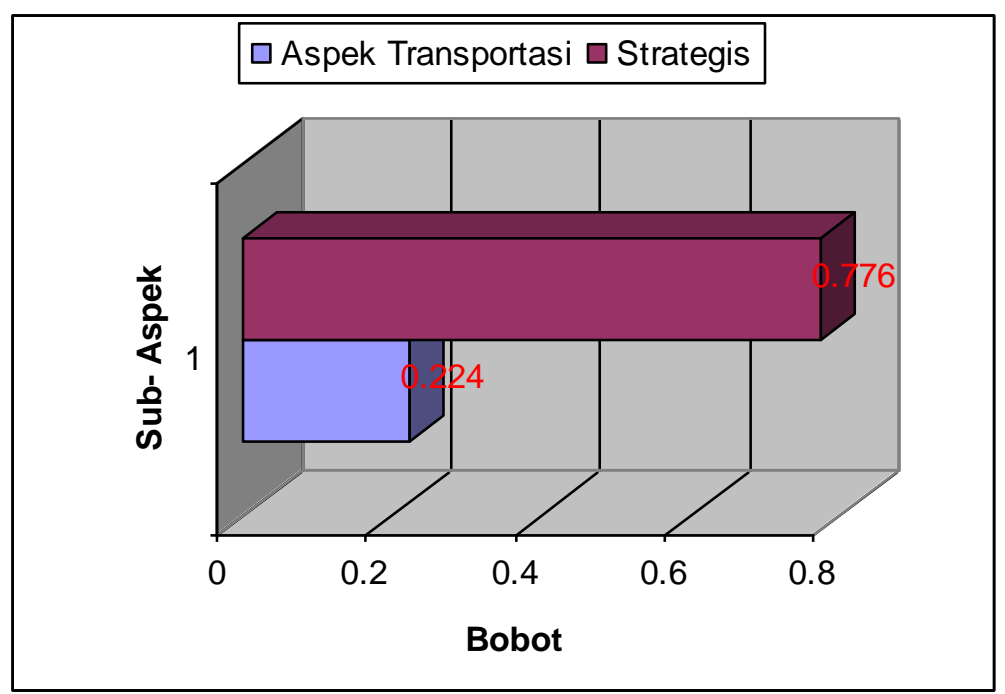

Sumber: Hasil Analisis , 2017.

\section{Gambar 11. Diagram Batang Bobot Sub- Aspek dari Aspek Aksesibilitas yang Mempengaruhi Penentuan Lokasi Koridor Distro dan Butik di Kota Pontianak}




\section{Pembobotan Alternatif Lokasi}

Dari ke 10 (sepuluh) sub-aspek yang menjadi kriteria untuk memilih lokasi koridor jalan untuk fungsi distro dan butik outlet, maka di dapati bobot penilaian tertinggi adalah Koridor Jalan Gusti Hamzah dengan nilai $(0,5253)$ di ikuti koridor Jalan M.Yamin dengan nilai bobot $(0,2555)$ dan yang terakhir adalah koridor Jalan Danau Sentarum dengan nilai bobot $(0,2154)$. Koridor Jalan Gusti Hamzah mengungguli 9 (sembilan) kriteria sub aspek, hanya satu aspek yang kalah yaitu sub aspek nilai historis yang dimenangkan koridor Jalan Danau Sentarum. Untuk lebih jelas dapat dilihat pada tabel berikut ini.

Tabel 3. Penilaian Masing-Masing Koridor terhadap 10 sub-aspek

\begin{tabular}{clc}
\hline No & \multicolumn{1}{c}{ Alternatif Lokasi } & Nilai \\
\hline 1 & Jalan Danau Sentarum & 0.2154 \\
2 & Jalan Prof. M. Yamin & 0.2555 \\
3 & Jalan Gusti Hamzah & 0.5253 \\
\hline
\end{tabular}

Sumber : Hasil Analisis, 2017

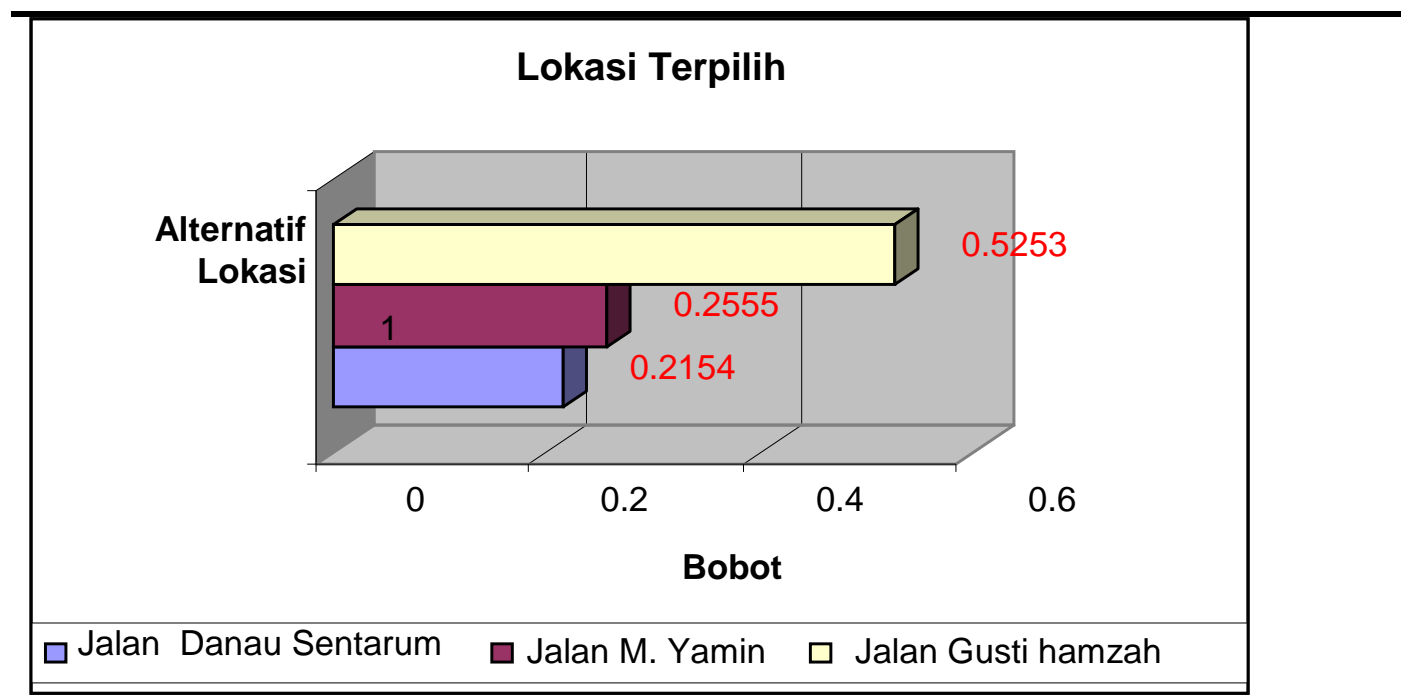

Sumber: Hasil Analisis , 2017.

\section{Gambar 11. Diagram Batang Bobot Alternatif Lokasi Terpilih}

\section{KESIMPULAN}

Dalam hasil perhitungan data terhadap berbagai aspek yang menjadi kriteria yaitu aspek Fisik, Sosial, ekonomi dan aksesibilitas didapati bobot penilaian antara lain ;

1. Aspek Ekonomi ( bobot penilaian $=0,45$ )

2. Aspek Sosial ( bobot penilaian $=0,24$ )

3. Aspek Fisik ( bobot penilaian $=0,20$ )

4. Aspek Aksesibilitas ( Bobot penilaian $=0,11$ )

Aspek-aspek tersebut merupakan (Level 1), dimana diuraikan dengan sub-aspek yang menjadi ( level 2 ), dari hasil perhitungan didapati hasil untuk aspek ekonomi sub-aspek tertinggi adalah daya tarik investasi (bobot penilaian $=0,481$ ), untuk aspek sosial penilaian sub-aspek yang tertinggi adalah aspek legalitas ( bobot penilaian $=0,515$ ) dan untuk aspek fisik sub-aspek penilaian tertinggi adalah kondisi fisik internal ( bobot penilaian $=$ 0,83 ) sedangkan untuk aspek asesibilitas sub kriteria penilaian tertinggi adalah aspek strategis $($ bobot penilaian $=0,776)$. 
Dinilai dari aspek tersebut, hirarki tertinggi adalah aspek ekonomi dengan sub aspek yang tertinggi adalah daya tarik investasi dimana yang menjadi tolak ukur kriteria adalah perputaran uang (cash flow) dalam jumlah yang besar, ramai oleh pengunjung, terutama pada saat weekend, harga lahan yang terus meningkat, bebas dari pungutan liar yang dapat menjadi beban bagi para pengusaha / investor. Pada aspek sosial yang menjadi penilaian tertinggi adalah sub aspek legalitas dimana yang menjadi tolok ukur adalah kesesuaian dengan peraturan tata ruang dan peraturan bangunan yang ditetapkan oleh pemda Kota Pontianak. Untuk aspek fisik yang menjadi penilaian tertinggi adalah sub aspek fisik internal dimana yang menjadi tolok ukur adalah kondisi kawasan yang lebih nyaman dan ketersediaan lahan untuk pengembangan dimasa yang akan datang. Sedangkan untuk aspek aksesibilitas penilian yang tertinggi adalah sub aspek strategis dimana yang menjadi tolok ukur adalah dekat dengan akses / pintu toll dekat / mudah dicapai dari pusat kota perjalanan untuk mencapai ke kawasan tersebut tidak menghabiskan waktu yang lama.

Dari ke 10 (sepuluh) sub-aspek tersebut menjadi kriteria untuk menilai ke tiga koridor jalan untuk penentuan lokasi distro dan butik outlet, didapati hasil sebagai berikut:

1. Koridor Jalan Danau Sentarum ( bobot penilaian $=0,5252$ )

2. Koridor Jalan Prof M. Yamin ( bobot penilaian $=0,2555$ )

3. Koridor Jalan Gusti Hamzah ( bobot penilaian = 0,2154)

Maka keputusan yang didapati dengan mengunakan Analytic Hierarchy Process (AHP) ini adalah koridor Jalan Gusti Hamzah, dimana dari 10 sub aspek, koridor Jalan Gusti Hamzah unggul dengan 9 (sembilan ) sub-aspek, hanya satu sub-aspek nilai historis yang dimenangkan koridor Jalan Danau Sentarum. Studi ini merupakan salah satu teknik evaluasi awal dalam menentukan lokasi koridor jalan untuk distro dan butik outlet dengan aspek dan sub-aspek yang telah ditentukan. Dimana evaluasi tidak menyatakan apa yang harus dibuat, namun hanya menyatakan ini baik dan ini buruk. Dalam hal ini evaluasi dalam menentukan koridor jalan untuk distro dan butik outlet adalah lokasi koridor Jalan Gusti Hamzah dengan bobot penilian 2 kali lebih unggul dari koridor Jalan Prof. M. Yamin maupun koridor Jalan Danau Sentarum.

\section{UCAPAN TERIMA KASIH}

Ucapan terimakasih kepada Unit Penelitian dan Pengabdian Masyarakat Politeknik Negeri Pontianak yang sudah memberikan bantuan dana Penelitian Terapan PNBP Polnep Tahun 2017.

\section{DAFTAR PUSTAKA}

Carr, Stephen, 1973, City, Sign and Light : a Policy Study, MIT Press, Cambridge.

Cullen, Gordon. 1961. The Concise ofTownscape. Van Nostrand Reinhold Company, New York.

Hudalah, Delik. 2004. Penentuan Prioritas Lokasi Pengembangan Kawasan Komersial di Kota Bogor. Departemen Teknik Planologi Fakultas Teknik Sipil dan Perencanaan ITB.

Krier, Rob. 1979. Urban Space. Rizzoli International Publications. New York.

Latan H, Ghozali I. 2012. Partial Least Square Konsep,Teknik Dan Aplikasi Menggunakan Smartpls 2.0 M3.Semarang (ID): Badan Penerbit Universitas Diponogoro.

Mandaka, Mutiawati. 2015. Estetika Visual Koridor Pada Bangunan-Bangunan Komersil di Jalan Pandanaran Semarang. Neo Teknika Desember 2015 hal 48-53.

Mokodongan, F. Elvie. Tallei. R.Vierta. 2016. Prinisp Desain Koridor Komersial di Kawasan Kota Tua Gorontalo. Prosiding Temu Ilmiah IPLBI 2016 hal. 1-8.

Murti, Cipto dan Wijaya, Bina, Holi. 2013. Pengaruh Kegiatan Komesial Terhadap Fungsi Bangunan Bersejaah di Koridor Jalan Malioboro Jogyakarta. Jurnal TeknikPWK Volume2 Nomor 12013.

Nugrahini, Conytin, Fibria. 2015. Quality Road as an Essential Part of City Image Sustainability Case Study : Corridor South Side of Kejawan Putih Tambak Surabaya. Jurnal Light Voll. 8 No. 1 April 2015 Universitas Muhammadiyah Surabaya. 
Saaty, T. L. (1993). Pengambilan Keputusan Bagi Para Pemimpin : Proses Hirarki Analitik untuk Pengambilan Keputusan dalam Situasi yang Kompleks terjemahan Decisions Making for Leaders : The Analytical Hierarchy Process for Decissions in Complex World. LPPM dan PT. Pustaka Binaman Pressindo. Jakarta.

Saaty, Thomas L. (1994). Fundamental of Decision Making and Priority Theory with The Analytic Hierarchy Process. Pittsburgh: RWS Publications.

Suri, Nur Sukma dan Sugiri, Agung. 2015. Persepsi dan Preferensi Masyarakat Terhadap Fasad Bangunan di Koridor Jalan Ki Samaun Kota Tangerang. Jurnal Tata Loka Volume 17 Nomor 3 Agustus 2015, 148160 Universitas Diponegoro Semarang.

Taufan, Muhammad. (1996). "Penerapan model Analisis Proses Hirarki (AHP) dalam penentuan prioritas usulan rencana proyek pembangunan prasarana dan sarana dasar dalam rapat koordinasi pembangunan di Kabupaten daerah tingkat II Bekasi, Jawa Barat”. Bandung : Tesis. Program Magister Perencanaan Wilayah dan Kota (PWK) - ITB.

Tobing, Rosaline, Rumiati. Siahaan, Uras. Dewi, Julia. 2014. Karakteristik Fisik Koridor Komersial Antar Kota Baru Dalam Kaitannya Dengan Penataan Periferi Kawasan Terstruktur dan Regulasi Kasus Studi: Koridor Serpong Tangerang Selatan. LPPM Universitas Katolik Parahyangan.

Widiantara, Andhika, I Wayan. Prwanto Edi. Sardjono, Budi, Agung. 2017. Unsur Pemandangan Berseri/Serial Vision Sebagai Pembentuk Karakter Visual Koridor Jalan Letjen Suprapto, Kawasan Kota Lama Semarang. Jurnal Modul Vol. 17 No. 1 Juli-Desember 2017. 